\title{
A nationwide structure for valid long-term oxygen therapy: 29-year prospective data in Sweden
}

\author{
This article was published in the following Dove Press journal: \\ International Journal of COPD \\ 30 October 2017 \\ Number of times this article has been viewed
}

\author{
Magnus Ekström ${ }^{1,2}$ \\ Zainab Ahmadi' \\ Hillevi Larsson' \\ Tove Nilsson ${ }^{2}$ \\ Josefin Wahlberg ${ }^{2}$ \\ Kerstin E Ström' \\ Bengt Midgren'
}

'Department of Clinical Sciences, Division of Respiratory Medicine \& Allergology, Lund University, Lund, ${ }^{2}$ Department of Medicine, Blekinge Hospital, Karlskrona, Sweden
Correspondence: Zainab Ahmadi

Department of Clinical Sciences, Division of Respiratory Medicine \& Allergology, Lund University, SE-22I 00 Lund, Sweden Tel +46 46 I7I 000

Email zai.ahmd@gmail.com
Background: Long-term oxygen therapy (LTOT) improves prognosis in COPD with severe hypoxemia. However, adherence to criteria for eligibility and quality of LTOT is often insufficient and varies between countries. The aim of this study was to evaluate a national structure for prescription and management of LTOT over three decades in Sweden.

Methods: The study was a prospective, population-based study of 23,909 patients on LTOT from 1987 to 2015 in the Swedish National Register of Respiratory Failure (Swedevox). We assessed the prevalence, incidence, and structure of LTOT; completeness of registration in Swedevox; and validity of prescription and management of LTOT in Sweden according to seven published quality indicators.

Results: LTOT was prescribed by 48 respiratory or medicine units and managed mainly by specialized oxygen nurses. Swedevox had a stable completeness of $85 \%$ of patients starting LTOT since 1987. The national incidence of LTOT increased from 3.9 to 14.7/100,000 inhabitants over the time period. In 2015, 2,596 patients had ongoing therapeutic LTOT in the registry, a national prevalence of 31.6/100,000. Adherence to prescription recommendations and fulfillment of quality criteria was stable or improved over time. Of patients starting LTOT in 2015, $88 \%$ had severe hypoxemia (partial pressure of arterial oxygen $\left[\mathrm{PaO}_{2}\right]<7.4 \mathrm{kPa}$ ) and $97 \%$ had any degree of hypoxemia $\left(\mathrm{PaO}_{2}<8.0 \mathrm{kPa}\right) ; 98 \%$ were prescribed oxygen $\geq 15$ hours/day or more; $76 \%$ had both stationary and mobile oxygen equipment; $75 \%$ had a mean $\mathrm{PaO}_{2}>8.0 \mathrm{kPa}$ breathing oxygen; and $98 \%$ were non-smokers.

Conclusion: We present a structure for prescription, management, and follow-up of LTOT. The national registry effectively monitored adherence to prescription recommendations and most likely contributed to improved quality of care.

Keywords: LTOT, oxygen, respiratory failure, hypoxemia, COPD

\section{Introduction}

Long-term oxygen therapy (LTOT) is an established treatment to improve the survival time of patients with COPD and chronic severe hypoxemia (therapeutic indication). ${ }^{1,2}$ The eligibility criteria for therapeutic LTOT are diagnosed COPD and severe resting hypoxemia (a partial pressure of arterial oxygen $\left[\mathrm{PaO}_{2}\right]$ of $<7.4 \mathrm{kPa}[55 \mathrm{mmHg}]$ breathing air) despite optimal therapy for the underlying disease(s). ${ }^{3}$ Therapeutic LTOT is also recommended by guidelines for COPD patients with moderate hypoxemia $\left(\mathrm{PaO}_{2} 7.4-8.0 \mathrm{kPa}\right.$ [56-59 $\mathrm{mmHg}]$ ) with concomitant signs of right-sided heart failure, pulmonary hypertension, or secondary polycythemia. ${ }^{1-5}$ The recent Long-Term Oxygen Treatment Trial reported no benefit from LTOT in terms of prognosis, rate of hospitalization, or health-related quality of life in COPD patients with mild to moderate hypoxemia. ${ }^{6}$

Adherence to eligibility and quality criteria of LTOT varies markedly between countries and is often insufficient. ${ }^{7-17}$ In a recent study in a health district in Spain 
of 406 LTOT patients, 50\% had COPD and only $47 \%$ of patients on LTOT had a $\mathrm{PaO}_{2}<8 \mathrm{kPa}$ when breathing air. ${ }^{10}$ Patients were frail and often had insufficient adherence to the therapy. Management, including that of smoking during oxygen therapy, also differs substantially between countries and settings. ${ }^{9,18,19}$ The lack of adequate LTOT prescription and management may contribute to poor clinical outcomes and impaired prognosis for the individual and increased costs for the society. ${ }^{1-3}$

A structured approach for valid prescription and management of LTOT is needed. ${ }^{10}$ The prevalence of LTOT is relatively high, ${ }^{20,21}$ and the incidence is projected to rise in the coming decades, especially among women. ${ }^{20}$ LTOT is associated with considerable logistics and costs. ${ }^{21,22}$ When inappropriately used, LTOT might also be an unnecessary burden for patients. Being connected to oxygen equipment has been associated with feelings of shame, restrictions of daily activities, and social isolation, contributing to poor compliance with LTOT. ${ }^{16,23}$ Considering the high burden and high costs of LTOT and the impact on patients' health-related quality of life, the adherence to LTOT guidelines should be monitored carefully.

Patients starting LTOT in Sweden are prospectively registered in the Swedish National Register of Respiratory Failure (Swedevox) since 1987. Swedevox was originally started by The Swedish Society of Chest Medicine and is integrated into routine clinical workflow nationwide. The registry provides a unique base for quality development and prospective collection of clinical and research data, quality assessment, and feedback to the clinical units in charge of the oxygen therapy. ${ }^{24}$ Validity of the management of LTOT in Sweden has not been comprehensively evaluated.

The aim of the present study was to describe and evaluate the national structure over the last three decades in Sweden in terms of valid prescription and management of LTOT.

\section{Methods}

\section{Study design}

This was a national, population-based, observational, longitudinal study of LTOT in Sweden. The structure of LTOT was assessed in 2014 through a web-based questionnaire sent to all units prescribing LTOT. The completeness of the Swedevox registry of patients starting LTOT was assessed using a postal questionnaire to all prescribing units approximately every other year since 1987, with the latest assessment in 2014. The incidence, prevalence, and the quality of prescription and management of LTOT were assessed using the Swedevox registry between 1 January, 1987 and 31 December, 2015.

\section{Data sources and assessments}

Structure of LTOT in Sweden

LTOT is prescribed by specialists in pulmonary medicine or internal medicine. ${ }^{25}$ All clinics prescribing LTOT in Sweden have agreed to observe the guidelines from the Swedish Respiratory Society, which are in line with international guidelines. The oxygen equipment is provided to the patient by specialized oxygen nurses or sometimes by oxygen technicians at each clinical unit. The oxygen nurses provide information, follow-up of the LTOT (often including home visits), and enter data in Swedevox. Each clinical unit is responsible for the prescription and management of LTOT. The structure of LTOT services was assessed in 2014 through a web-based questionnaire (Figure S1) to all departments prescribing LTOT. The questionnaire was answered by the oxygen nurses and physicians responsible for the LTOT and comprised 26 questions on organization, allocated resources, personnel (number, education, and experience), provision of oxygen equipment, provision of home visits, assessment and management of smoking, cognitive impairment, provision and follow-up of palliative oxygen, assessment of an exertional oxygen dose using an exercise test, reassessment of the LTOT indication, and registration in Swedevox.

\section{Swedevox}

The Swedevox registry was started in 1987 due to the regional differences in access to, and the performance of, LTOT in Sweden. ${ }^{24}$ Swedevox is supported by Swedish Respiratory Society and financed by the government through the Swedish Association of Local Authorities and Regions.

Swedevox contains baseline data (at the time of starting LTOT) on resting $\mathrm{PaO}_{2}$ and partial pressure of arterial carbon dioxide $\left(\mathrm{PaCO}_{2}\right)$ breathing air and during oxygen therapy, forced expiratory volume in 1 second, measured body mass index, smoking history, WHO performance status, prescribed daily dose (1/minute) and duration (hour/day) of LTOT. Patients prescribed LTOT for therapeutic purpose (ie, nonpalliative LTOT) for all underlying diagnoses were included in this study. The variables in Swedevox are summarized in Table S1.

\section{Completeness}

The completeness of Swedevox regarding patients starting LTOT was assessed by a postal questionnaire to all prescribing units approximately every other year since 1987 , 
with the latest assessment in 2014. Self-reported reasons for not registering patients starting LTOT (missing data) were reported by the nurse or physician responsible for the LTOT at each unit in 2014. In 2013, we also made an attempt to analyze completeness via the National Patient Registry of the Swedish Board of Health and Welfare. It turned out that the completeness in the Patient Register, due to missing procedural codes for oxygen therapy, was one-third of those of Swedevox.

\section{Quality of LTOT}

Quality of LTOT prescription and management was assessed using Swedevox according to seven published quality indicators: ${ }^{26} \mathrm{PaO}_{2}$ breathing air $<7.4 \mathrm{kPa}$ at starting LTOT; no current smoking; low number of thoracic deformity patients without concomitant home mechanical ventilation; oxygen prescribed $\geq 15$ hours/day; mobile oxygen to ambulatory patients; reassessment of hypoxemia when LTOT was started in relation to an exacerbation; and avoidance of continuous (maintenance) treatment with oral glucocorticoids in COPD.

\section{Ethical considerations}

The study was approved by the Lund University Research Ethics Committee (Dnr: 2010/315 and 2011/722). All regional ethics committees in Sweden, the National Board of Health and Welfare, and the Data Inspection Board approved establishment of the Swedevox registry. All patients participating in the study were informed according to directives from the authorities. Participants provided their verbal informed consent when registered in Swedevox as written informed consent from included patients in the registry was not required by Swedish research regulations. The analysis database was de-identified and stored and handled confidentially by ME at the Department of Medicine, Blekinge Hospital.

\section{Statistical analyses}

Data were tabulated using frequencies and percentages for categorical variables, mean with standard deviation (SD) and median with range or interquartile range for continuous variables with normal and skewed distribution, respectively.

Incidence and prevalence of LTOT in Swedevox were calculated per 100,000 person-years for the Swedish general population for each calendar year from the National Population Register. The national incidence and prevalence were calculated by dividing the corresponding figures in Swedevox with the completeness of the registry $(0.85)$. The completeness was constant during the study period.
Quality indicators of LTOT were tabulated for 2015 and over the study period from 1987 to 2015 to evaluate the temporal pattern. The proportion of patients starting LTOT for COPD with severe hypoxemia was calculated. ${ }^{1,2,6,27}$ Time trend in the LTOT indications were explored by plotting the mean $\mathrm{PaO}_{2}$ (air) $\pm 2 \mathrm{SD}$ per calendar year and analyzed using linear regression. Statistical significance was defined as a two-tailed $p<0.05$. Analyses were conducted with Stata version 14.2 (StataCorp LP, College Station, TX, USA).

\section{Results}

\section{Structure of LTOT in Sweden}

The questionnaire was sent to all units prescribing LTOT in Sweden ( $n=48)$ and was answered by 43 units; response rate was $90 \%$. Characteristics of the national structure of LTOT are shown in Table 1. The oxygen service is provided within respiratory or internal medicine clinics in Sweden. In most cases, a physician is responsible for LTOT management and sets the medical diagnosis for the patient before prescribing LTOT. The evaluation of the indication for LTOT is conducted as inpatient in the ward or at an outpatient clinic. Checklists are very often used for guidance when starting the patient on LTOT. Home visits are carried out routinely in $70 \%$ of LTOT units and in selected cases in $14 \%$ of units. Withdrawal attempts within 3 months are not routinely done by $40 \%$ of LTOT units. Half of units use a non-smoking agreement with the patient before starting LTOT. Patients are registered in Swedevox mostly within a month (74\%) of starting LTOT.

\section{Completeness of Swedevox and reasons for missing data}

All 48 units prescribing LTOT in Sweden report to Swedevox, and the completeness of patients starting LTOT was stable at about 85\% since 1987. Reasons for not registering patients in Swedevox were reported by units as mainly shortage of time and that registration was simply forgotten in some patients. No unit indicated that only selected patients were registered (no selective reporting). Data on $\mathrm{PaO}_{2}$ (air) that were almost complete in the first years of the registry showed $20 \%$ missing during the recent 10 years. The increased rate of missing blood gases is, however, related to an increased use and reporting of oxygen saturation ( $40 \%$ of patients with reported arterial blood gas test). If combining data on saturation and blood gas measurement breathing air, the rate of missing data on oxygenation at startup has been stable in the recent 15 years at about $10 \%$. Spirometry data are missing for almost half of the patients, a doubling during the same 
Table I The national structure of LTOT in Sweden

\begin{tabular}{ll}
\hline Assessments (N responding units) & Units (\%) \\
\hline $\begin{array}{l}\text { A physician is responsible for LTOT management } \\
\text { ( } \mathrm{n}=42 \text { ) }\end{array}$ & 3 I (74) \\
A diagnosis is set by a physician before prescribing & $39(95)$ \\
LTOT ( $\mathrm{n}=4 \mathrm{I})$ & \\
The health intervention code AG062 is registered to a physician's \\
appointment or inpatient occasion when starting LTOT ( $\mathrm{n}=4 \mathrm{I})$ : \\
Always & $5(12)$ \\
Sometimes & $8(20)$ \\
Never or don't know what it's about & $28(68)$ \\
Full-time employments (40 hours/week) allocated & $15(37)$ \\
to oxygen personnel (registered nurses, assistant & \\
nurses, or physiotherapists) & \\
Oxygen personnel (nurses or physiotherapists) working at the \\
outpatient clinic with LTOT patients: \\
5 days/week & $26(60)$ \\
$3-4$ days/week & $9(21)$ \\
The oxygen service is provided within the following organization: \\
Respiratory clinic & $28(65)$ \\
Internal medicine clinic & $6(14)$ \\
Independent clinic & I (2) \\
Other organization & $8(18)$
\end{tabular}

Organization of personnel, ie, if nurses, physiotherapists, technicians work entirely with oxygen or with other services as well:

Entirely with oxygen therapy $8(18)$

Shared with CPAP or home ventilation $9(20)$

Shared with allergy clinic 10 (23)

Together with lung clinic 25 (57)

Other service 14 (32)

Oxygen courses attended by some of the personnel:

Oxygen course arranged by Swedevox 24 (55)

AGA 25 (57)

AIOLOS 20 (45)

Philips Respironics 19 (43)

Other course 9 (20)

Work experience with LTOT patients of the most experienced

oxygen nurse:

Less than I year

Less than 5 years

0

More than 5 years

II (26)

$32(74)$

Home visits carried out in LTOT patients:

Routinely

In selected cases

No home visits

$30(70)$

$6(14)$

$7(16)$

Reevaluation within 3 months of LTOT start:

Routine reevaluation

$9(20)$

Routine reevaluation of LTOT started after

$10(23)$

exacerbation

Sometimes $\quad 7$ (17)

No $17(40)$

The oxygen equipment and information about LTOT if provided to patients at home by:

Oxygen nurses $\quad 33(77)$

Technicians $8(18)$

Other personnel 2 (5)

Use of checklists as help at the initiation of LTOT 36 (83)

A separate list of the patients prescribed LTOT is $\quad 42$ (98)

kept, in addition to the Swedevox registration
Table I (Continued)

\begin{tabular}{|c|c|}
\hline Assessments (N responding units) & Units (\%) \\
\hline $\begin{array}{l}\text { Patients sign a non-smoking agreement before } \\
\text { starting LTOT }\end{array}$ & $23(53)$ \\
\hline \multicolumn{2}{|l|}{ Smoking is assessed after start of LTOT (COHb/urine): } \\
\hline Yes, routinely & $4(9)$ \\
\hline Yes, but only when smoking is suspected & $9(20)$ \\
\hline No & $30(70)$ \\
\hline $\begin{array}{l}\text { A cognitive assessment (eg, MMT) is performed } \\
\text { before LTOT startup }\end{array}$ & $5(12)$ \\
\hline Time dedicated for registration in Swedevox & $14(33)$ \\
\hline \multicolumn{2}{|l|}{ Patients are registered in Swedevox within $(n=42)$ : } \\
\hline A week of LTOT start & $18(43)$ \\
\hline A month of LTOT start & $13(3 \mid)$ \\
\hline \multicolumn{2}{|c|}{ When prescribing LTOT, the evaluation is normally done at: } \\
\hline Inpatient on the ward & $40(92)$ \\
\hline Outpatient clinic & $29(66)$ \\
\hline The patient's home & $3(7)$ \\
\hline Other & $I(2)$ \\
\hline $\begin{array}{l}\text { In patients with } \mathrm{CO}_{2} \text { retention }\left(\mathrm{PaCO}_{2}>6.5 \mathrm{kPa}\right) \text {, } \\
\text { LTOT is evaluated in hospital }(\mathrm{n}=38)\end{array}$ & $32(84)$ \\
\hline \multicolumn{2}{|c|}{$\begin{array}{l}\text { A routine walk test is carried out with the prescribed oxygen dose } \\
\text { before LTOT is prescribed: }\end{array}$} \\
\hline Yes always, patients walk for 6 minutes & $5(12)$ \\
\hline Yes, patient walk 500 meters & $8(18)$ \\
\hline Sometimes & $15(35)$ \\
\hline No & $15(35)$ \\
\hline $\begin{array}{l}\text { Feedback received from data in Swedevox to the } \\
\text { LTOT clinic, eg, annually }(n=4 I)\end{array}$ & $2 I(5 I)$ \\
\hline
\end{tabular}

Notes: The structure of LTOT services was assessed in 2014 through a webbased questionnaire to all units prescribing LTOT in Sweden. The coverage for the questionnaire was $90 \%$ (43 out of 48 clinics answered the questionnaire).

Abbreviations: $\mathrm{CoHb}$, carboxyhemoglobin; LTOT, long-term oxygen therapy; MMT, Mini Mental Test; $\mathrm{PaCO}_{2}$, partial pressure of arterial carbon dioxide.

time period. Spirometry data were lacking in $48 \%$ of patients starting LTOT with physician-diagnosed COPD.

\section{Prevalence and incidence of LTOT}

Between 1987 and 2015, a total of 23,909 patients started LTOT in the Swedevox registry. Four hundred (2\%) of the patients started LTOT more than once. The mean age of patients starting LTOT increased from 66 to 76 years, and the percentage of women increased from $43 \%$ to $58 \%$ during the study period. Airways disease was the main underlying cause for prescribing LTOT ( $\mathrm{n}=15,840 ; 69 \%)$ with 14,420 (62\%) patients having physician-diagnosed COPD (Figure 1).

Between 1987 and 2015, the national incidence of LTOT increased linearly from 3.9 to 14.7 per 100,000 inhabitants. By the end of 2015, a total of 2,596 patients received ongoing LTOT in Swedevox, corresponding to a national prevalence of 30.6 per 100.000 inhabitants.

\section{Validity and quality of LTOT over time}

Mean $\mathrm{PaO}_{2}$ breathing ambient air before LTOT start was $6.5(\mathrm{SD}, 0.9) \mathrm{kPa}$ in 2015, and was stable throughout the study 


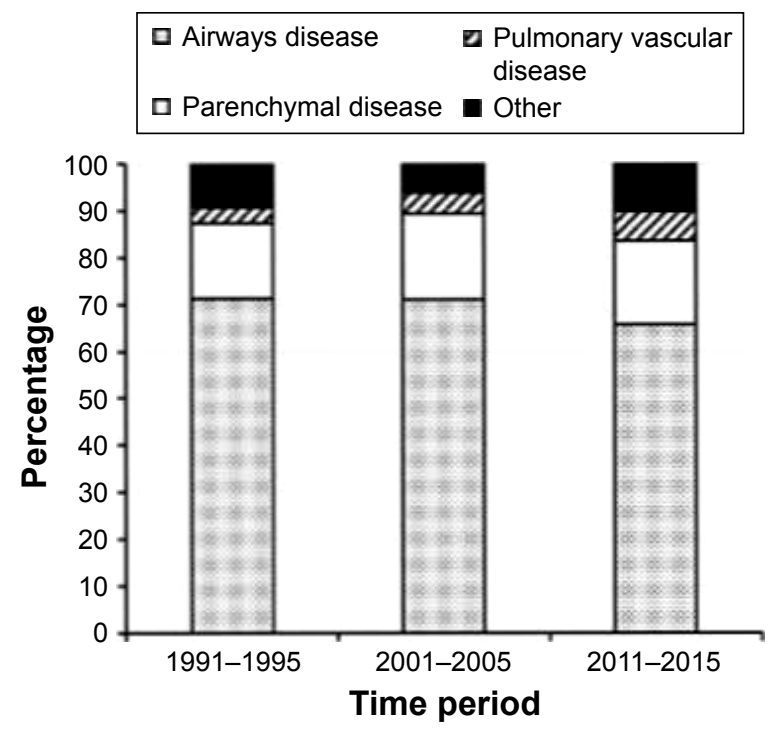

Figure I Primary physician-diagnosed cause for starting LTOT.

Notes: Reasons for starting LTOT: airways disease, parenchymal disease, pulmonary vascular disease, and other. Airways disease was the main underlying cause for prescribing LTOT (69\%).

Abbreviation: LTOT, long-term oxygen therapy.

period (Figure 2A). Of patients starting LTOT in 2015, 88\% fulfilled the criteria of severe hypoxemia $\left(\mathrm{PaO}_{2}<7.4 \mathrm{kPa}\right)$ and $97 \%$ had any degree of hypoxemia $\left(\mathrm{PaO}_{2}<8.0 \mathrm{kPa}\right)$, as shown in Table 2.

The mean $\mathrm{PaO}_{2}$ on oxygen was also stable during the study period at $8.6(\mathrm{SD}, 1.2) \mathrm{kPa}$ (Figure 2B). On LTOT, $75 \%$ of patients fulfilled the quality criteria of having a $\mathrm{PaO}_{2}>8.0 \mathrm{kPa}$ on oxygen. In multivariate logistic regression, factors independently associated with not achieving a $\mathrm{PaO}_{2}>8.0 \mathrm{kPa}$ on oxygen were hypercapnia before starting LTOT $\left(\mathrm{PaCO}_{2}>6.5 \mathrm{kPa}\right.$ breathing air), a $\mathrm{PaCO}_{2}$ on oxygen $>6.5 \mathrm{kPa}$, and a more recent start year of LTOT ( $p<0.001$ for all associations). There was no difference between men and women $(p=0.99)$.

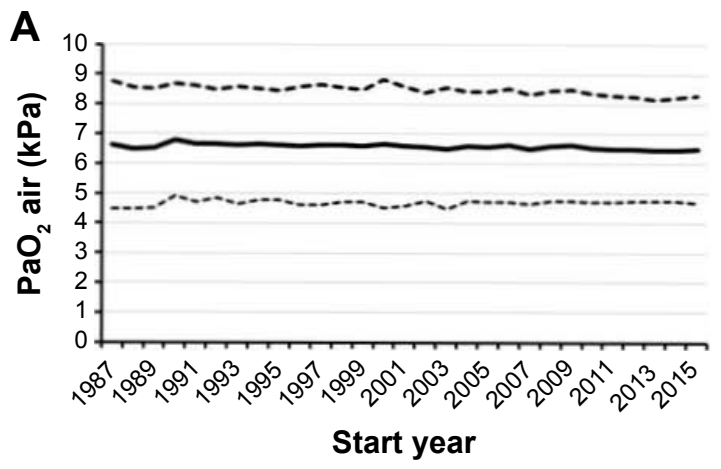

Oxygen was prescribed for 15 hours/day or more in $98 \%$ of patients (Figure $3 \mathrm{~A}$ ). In line with recommendations that mobile oxygen equipment should be prescribed to patients who spent time outside their home, $76 \%$ of patients starting LTOT in 2014 had mobile equipment at 1-year follow-up. Among patients who had mobile oxygen equipment, almost two-thirds used mobile concentrators, one-third compressed gas cylinders, and only $3 \%$ used liquid oxygen. The rate of non-smokers has been stable at $98 \%$ during the study period in accordance with current quality criteria (Figure 3B).

The proportion of patients starting LTOT with COPD with severe hypoxemia, which corresponds to the evidencebased indication as published evidence pertain to COPD, increased from $40 \%$ in 1987 to about 50\% during the last 20 years $(p=0.02)$.

\section{Discussion \\ Main findings}

Despite the marked increase in the incidence and age of patients starting LTOT, the Swedish national structure for LTOT practice is associated with high and sustained validity of prescription and management over three decades. The structure including specialized oxygen nurses at the responsible clinical centers and structured follow-up and feedback of practice through the national Swedevox registry have been consistent and may provide a model for improved management of LTOT in many settings.

\section{What this study adds}

The Swedevox registry is a well-functioning national structure for implementing, monitoring, and securing valid prescription and management of LTOT. Several reports have highlighted the need of structure to optimize LTOT

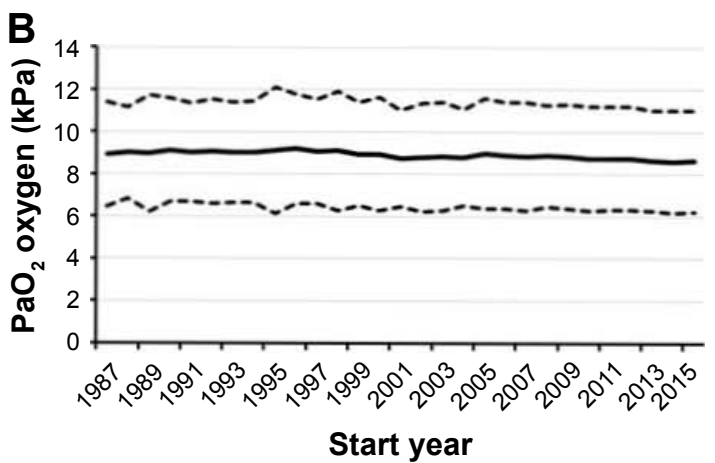

Figure $2 \mathrm{Mean}^{\mathrm{PaO}}$ on room air $( \pm 2 \mathrm{SD})(\mathbf{A})$ and mean $\mathrm{PaO}_{2}$ on oxygen $( \pm 2 \mathrm{SD})(\mathbf{B})$.

Notes: The mean $\mathrm{PaO}_{2}$ breathing ambient air before LTOT start was stable during the study period at $6.5(\mathrm{SD}, 0.9) \mathrm{kPa}$. The mean $\mathrm{PaO}$, on oxygen was stable during the study period at $8.6(\mathrm{SD}, \mathrm{I} .2) \mathrm{kPa}$.

Abbreviations: $\mathrm{PaO}_{2}$ (air), arterial blood gas tension of oxygen on air; SD, standard deviation; $\mathrm{PaO}_{2}$ (oxygen), arterial blood gas tension of oxygen on oxygen; LTOT, longterm oxygen therapy. 
Table 2 Quality of LTOT in Sweden in 2015

\begin{tabular}{lll}
\hline Quality criteria & $\begin{array}{l}\text { Aim, } \\
\% \text { of } \\
\text { patients }\end{array}$ & $\begin{array}{l}\text { Percentage } \\
\text { of patients } \\
\text { fulfilling criteria } \\
\text { in 2015 }\end{array}$ \\
\hline $\mathrm{PaO}_{2}$ (air) $<7.4 \mathrm{kPa}$ & $>85$ & 88 \\
$\mathrm{PaO}_{2}$ (oxygen) $\geq 8.0 \mathrm{kPa}$ & $>90$ & 75 \\
Current smokers & $<5$ & 2 \\
$\begin{array}{l}\text { Patients with thoracic deformity on } \\
\text { LTOT but without concomitant home }\end{array}$ & 0 & 0 \\
mechanical ventilation & & \\
$\begin{array}{l}\text { Mobile oxygen to ambulatory patients* } \\
\text { LTOT prescribed } \geq 16 \text { hours/day }\end{array}$ & $>50$ & 76 \\
Reevaluation of hypoxemia if & $>95$ & 98 \\
LTOT was started in relation to an & & 60 \\
exacerbation in 20I4 & & \\
$\begin{array}{l}\text { Maintenance treatment with oral } \\
\text { glucocorticoids in people with COPD }\end{array}$ & $<20$ & 15 \\
\hline
\end{tabular}

Note: *Assessed at follow-up after I year among patients starting LTOT in 2014. Abbreviations: LTOT, long-term oxygen therapy; $\mathrm{PaO}_{2}$ (air), arterial blood gas tension of oxygen on air; SD, standard deviation; $\mathrm{PaO}_{2}$ (oxygen), arterial blood gas tension of oxygen on oxygen.

prescription, adherence, and management; integrated care models have been suggested. ${ }^{10}$

The validity and quality of LTOT in Sweden may be explained by several factors: 1) LTOT in Sweden is prescribed mainly by specialists in respiratory medicine or internal medicine. LTOT is managed at each clinical center but is funded by the government; 2) when a patient fulfills LTOT criteria and is identified as eligible by the responsible specialist, contact is established with the specialized oxygen nurse(s) at the responsible clinical unit who manages the practical aspects of treatment and follow-up. The oxygen nurses in most cases hand over the oxygen equipment and information to the patient in the home, check the home condition regarding risk factors for fire including smoking, gas stove, and open fireplaces, and arranges for home adaptation by an occupational therapist as needed; and 3) continued smoking is an established contraindication for LTOT in Sweden. ${ }^{18}$ Patients are often informed at the initiation of LTOT about potential fire hazards and that the oxygen treatment may be discontinued if they resume smoking. In a recent study, only $2 \%$ of patients were smokers when starting LTOT in Sweden, compared to $21 \%$ in Denmark and $14 \%$ in Scotland. ${ }^{18}$ Information on local prescription patterns and quality of LTOT is disseminated to prescribing clinics through annual Swedevox reports, courses, meetings with nurses and physicians, and by direct contact with the clinical units. Since a couple of years, feedback is also offered through real-time user-specified reports from the Swedevox homepage. For the benefit of patients, relatives, laymen, politicians, and hospital administrators, these reports are public and access is not confined to the participating clinics.

\section{Strengths and limitations}

The Swedevox registry has a high national completeness and includes prospective data from three decades using a consistent structure. The high response rate (90\%) attained by the web-based questionnaire sent to all LTOT services allowed us to evaluate the validity of LTOT practice in Sweden. Prescription and follow-up of LTOT are financed through the Swedish Association of Local Authorities and Regions and cannot be purchased privately outside medical care, thus minimizing any economic incentives for reporting bias. Swedevox also has the potential for cross-linkage with
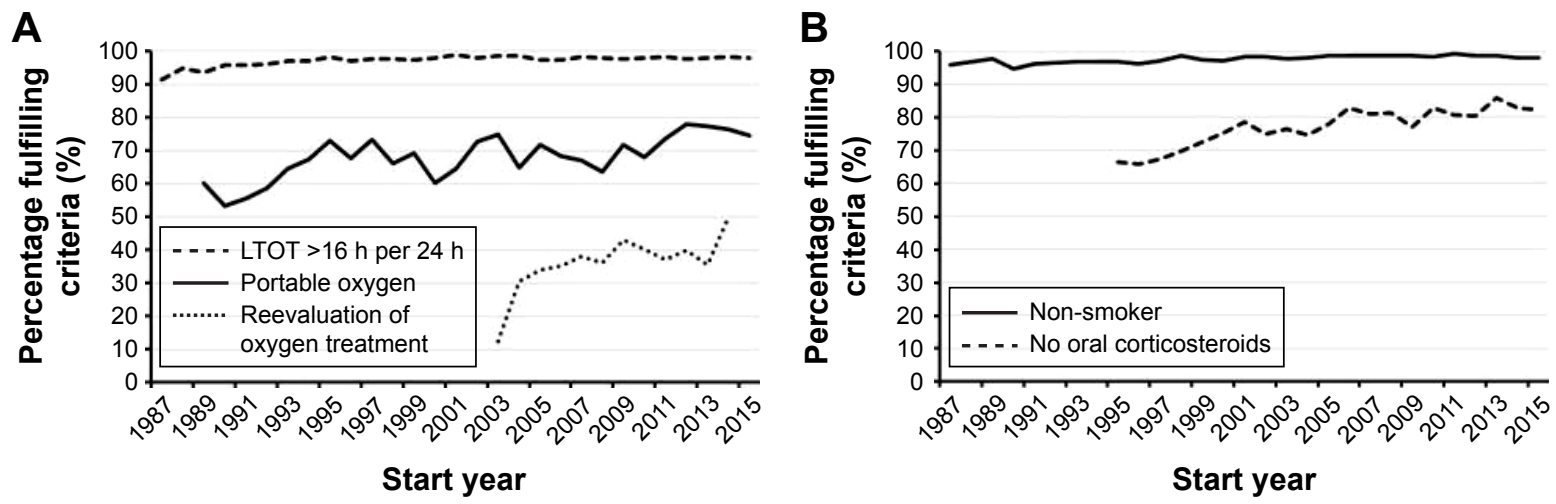

Figure 3 Percentage fulfilling criteria for LTOT prescription, oxygen delivery mode, and reevaluation of treatment (A) and percentage fulfilling quality criteria for LTOT (B). Notes: The criteria in (A) pertain to the percentage of LTOT patients with prescribed daily LTOT duration above I6 hours/day; portable oxygen at I-year follow-up, and reevaluation of hypoxemia when LTOT was started in relation to an exacerbation. Oxygen was prescribed for 15 hours/day or more in $98 \%$ of patients; prescription of mobile oxygen to ambulatory patients varied during the study period but the aim of $>50 \%$ was fulfilled; and an increase in reevaluation of oxygen treatment if started in relation to an exacerbation was seen during the study period. The criteria in (B) pertain to the percentage of LTOT patients being non-smokers and the absence of maintenance treatment with oral corticosteroids. The rate of non-smokers was stable at $98 \%$ during the study period, in accordance with the quality criteria. Maintenance treatment with oral glucocorticoids was low during the study period.

Abbreviation: LTOT, long-term oxygen therapy. 
other national health care registers using Swedish personal identity numbers. ${ }^{28-30}$

There are some limitations in the Swedevox registry. Data pertain mostly to baseline and we had limited data during the LTOT. Spirometry data were missing for as many as $48 \%$ of patients reported to have physician-diagnosed COPD. The high rate of missing spirometry data could reflect that over time, LTOT has been prescribed to more elderly patients who are likely to have multiple comorbidities and to be more frail and therefore might be less likely to have a spirometry performed before starting LTOT. Spirometry is important as it is required for the correct diagnosis of COPD, which is the evidence-based indication for LTOT. Data on reevaluation of LTOT are limited as the response rate was low. It is possible that LTOT was reevaluated but that a withdrawal test was not performed. To this end, this question has been changed in Swedevox in 2015 to capture reevaluation (with or without a withdrawal test). We lacked data on adherence to LTOT. Adherence is likely to be a central determinant for the effectiveness of LTOT and more research is needed to evaluate and improve adherence to LTOT, maybe by incorporating recent technical advances such as oxygen flow sensors.

\section{Identified areas for improvement}

Guidelines recommend initiation of LTOT when the patient is clinically stable on optimal medical treatment, and that the need of oxygen should be reevaluated at 3 months when LTOT is started in relation to an exacerbation. ${ }^{3}$ In the current study, reevaluation of hypoxemia was carried out in $60 \%$ of patients with known data. However, data on reevaluation were reported only for a minority of patients. Similarly, rates of reevaluation have been reported to be low at one center in Spain $^{10}$ and higher in Denmark. ${ }^{12}$

Currently, $75 \%$ of patients fulfill the criteria of a $\mathrm{PaO}_{2}>8.0 \mathrm{kPa}$ on oxygen. It is possible that the oxygen dose could be further optimized during LTOT to achieve better control of hypoxemia during rest, but the present findings suggest that the level of hypercapnia might limit the oxygen dose in some patients. In Sweden, these patients are not routinely offered long-term mechanical ventilation as an adjunct to LTOT. Eligibility and titration of LTOT should be based on blood gas measurements whenever possible as this was used in the efficacy trials ${ }^{1,2}$ and oxygen saturation is less reliable for determining the level of hypoxemia. ${ }^{3}$ Spirometry should be assessed before starting LTOT whenever possible. In Sweden, specialized oxygen nurses are responsible for the practical aspects and follow-up of LTOT, and titration of oxygen dose could be carried out more effectively.
The home visits carried out by the oxygen nurses serve several important functions with regard to informing patients and carers, analyzing any risk factors for fire and home adaptation if necessary.

\section{Implications}

The present findings support that a structured approach to prescription and management is associated with high and sustained validity of LTOT. Although cause and effect cannot be inferred from observational data, the consistent national structure and follow-up using the Swedevox registry is likely to have improved and sustained awareness of the indications and proper management of LTOT. As LTOT is one of few interventions to improve survival in patients with COPD and severe hypoxemia and is associated with considerable costs and logistics, ${ }^{21,22}$ improving LTOT management could improve prognosis for the individual and reduce health care costs. More research is needed on adherence to LTOT. We think that LTOT should be prescribed and managed by physicians with special training and follow-up of the therapy carried out by specialized oxygen staff, optimally combined with home visits; and the patients included in a registry for surveillance of quality of care, evidence-based implementation of changes in practice and research purpose. In Sweden, each patient's unique Swedish identification number facilitates follow-up of the therapy and could be used for cross-linking with other health care databases. An optimized management of LTOT is important to improve survival and quality of life of the individual patients with chronic hypoxemic respiratory failure.

\section{Conclusion}

The national registry effectively monitored adherence to prescription recommendations, and the presented structure might be suitable for implementation in other settings for improved and sustained validity of LTOT.

\section{Data sharing statement}

Data are available after approval from the Lund University Research Ethics Committee for researchers who meet the criteria for access to confidential data. Authors may be contacted to aid with the data access from Ethics Committee.

\section{Acknowledgments}

The authors would like to thank all the doctors and nurses at all LTOT units. ME was supported by unrestricted grants from The Swedish Society of Medicine, the Swedish Respiratory Society, the Swedish Heart-Lung Foundation, and 
the Scientific Committee of Blekinge County Council. The funders had no role in study design, data collection and analysis, decision to publish, or preparation of the manuscript.

\section{Author contributions}

ME had full access to all the data in the study and takes full responsibility for the integrity of the data and the accuracy of the data analysis. Conception and design: BM, HL, ME, ZA; acquisition of data: BM, HL, KES, ME; analysis of data: HL, JW, ME, TN, ZA; interpretation of data: BM, HL, JW, KES, ME, TN, ZA; drafting the article: HL, ME, ZA; and revision for important intellectual content and approval of the version to be published: BM, HL, JW, KES, ME, TN, ZA.

\section{Disclosure}

The authors report no conflicts of interest in this work.

\section{References}

1. Continuous or nocturnal oxygen therapy in hypoxemic chronic obstructive lung disease: a clinical trial. Nocturnal Oxygen Therapy Trial Group. Ann Intern Med. 1980;93(3):391-398.

2. Long term domiciliary oxygen therapy in chronic hypoxic cor pulmonale complicating chronic bronchitis and emphysema. Report of the Medical Research Council Working Party. Lancet. 1981;1(8222): 681-686.

3. Hardinge M, Annandale J, Bourne S, et al; British Thoracic Society Home Oxygen Guideline Development Group; British Thoracic Society Standards of Care Committee. British Thoracic Society guidelines for home oxygen use in adults. Thorax. 2015;70(Suppl 1):i1-i43.

4. Läkemedelsverket (Swedish Medical Products Agency). Läkemedelsbehandling av kroniskt obstruktiv lungsjukdom (KOL) - behandlingsrekommendation. 2015. Available from: https://lakemedelsverket.se/ kol. Accessed December 3, 2015.

5. Swedish National Register for Respiratory Failure (Swedevox). Guidelines for long-term oxygen therapy. 2015. Available from: www.ucr. uu.se/swedevox/. Accessed February 19, 2016.

6. Long-Term Oxygen Treatment Trial Research Group, Albert RK, $\mathrm{Au} \mathrm{DH}$, Blackford AL, et al. A randomized trial of long-term oxygen for COPD with moderate desaturation. N Engl J Med. 2016;375(17): $1617-1627$.

7. Wijkstra PJ, Guyatt GH, Ambrosino N, et al. International approaches to the prescription of long-term oxygen therapy. Eur Respir J. 2001; 18(6):909-913.

8. Ringbaek TJ. Home oxygen therapy in COPD patients. Results from the Danish Oxygen Register 1994-2000. Dan Med Bull. 2006;53(3): 310-325.

9. Ringbaek TJ, Lange P. The impact of the Danish Oxygen Register on adherence to guidelines for long-term oxygen therapy in COPD patients. Respir Med. 2006;100(2):218-225.

10. Hernandez C, Aibar J, de Batlle J, et al; NEXES Consortium. Assessment of health status and program performance in patients on long-term oxygen therapy. Respir Med. 2015;109(4):500-509.

11. Chailleux E, Fauroux B, Binet F, Dautzenberg B, Polu JM. Predictors of survival in patients receiving domiciliary oxygen therapy or mechanical ventilation. A 10-year analysis of ANTADIR Observatory. Chest. 1996;109(3):741-749.
12. Ringbaek TJ, Lange P. Trends in long-term oxygen therapy for COPD in Denmark from 2001 to 2010. Respir Med. 2014;108(3):511-516.

13. Muir JF, Voisin C, Ludot A. Organization of home respiratory care: the experience in France with ANTADIR. Monaldi Arch Chest Dis. 1993;48(5):462-467.

14. Verduri A, Ballerin L, Simoni M, et al. Poor adherence to guidelines for long-term oxygen therapy (LTOT) in two Italian university hospitals. Intern Emerg Med. 2014;9(3):319-324.

15. Kampelmacher MJ, Van Kesteren RG, Alsbach GP, et al. Prescription and usage of long-term oxygen therapy in patients with chronic obstructive pulmonary disease in The Netherlands. Respir Med. 1999; 93(1):46-51.

16. Neri M, Melani AS, Miorelli AM, et al; Educational Study Group of the Italian Association of Hospital Pulmonologists (AIPO). Long-term oxygen therapy in chronic respiratory failure: a Multicenter Italian Study on Oxygen Therapy Adherence (MISOTA). Respir Med. 2006; 100(5):795-806.

17. Morrison D, Skwarski K, MacNee W. Review of the prescription of domiciliary long term oxygen therapy in Scotland. Thorax. 1995;50(10): 1103-1105.

18. Tanash HA, Huss F, Ekström M. The risk of burn injury during longterm oxygen therapy: a 17-year longitudinal national study in Sweden. Int J Chron Obstruct Pulmon Dis. 2015;10:2479-2484.

19. Sharma G, Meena R, Goodwin JS, Zhang W, Kuo YF, Duarte AG. Burn injury associated with home oxygen use in patients with chronic obstructive pulmonary disease. Mayo Clin Proc. 2015;90(4): 492-499.

20. Franklin KA, Gustafson T, Ranstam J, Ström K. Survival and future need of long-term oxygen therapy for chronic obstructive pulmonary disease - gender differences. Respir Med. 2007;101(7):1506-1511.

21. Croxton TL, Bailey WC. Long-term oxygen treatment in chronic obstructive pulmonary disease: recommendations for future research: an NHLBI workshop report. Am J Respir Crit Care Med. 2006;174(4): 373-378.

22. Stoller JK, Panos RJ, Krachman S, Doherty DE, Make B; Longterm Oxygen Treatment Trial Research Group. Oxygen therapy for patients with COPD: current evidence and the long-term oxygen treatment trial. Chest. 2010;138(1):179-187.

23. Ring L, Danielson E. Patients' experiences of long-term oxygen therapy. J Adv Nurs. 1997;26(2):337-344.

24. Ström K, Boe J. A national register for long-term oxygen therapy in chronic hypoxia: preliminary results. Eur Respir J. 1988;1(10):952-958.

25. The Swedevox Register. Annual report 2015. Available from: http:// www.ucr.uu.se/swedevox/. Accessed November 7, 2016.

26. Gustafson T, Löfdahl K, Ström K. A model of quality assessment in patients on long-term oxygen therapy. Respir Med. 2009;103(2): 209-215.

27. Cranston JM, Crockett AJ, Moss JR, Alpers JH. Domiciliary oxygen for chronic obstructive pulmonary disease. Cochrane Database Syst Rev. 2005;(4):CD001744.

28. Ahmadi Z, Lundström S, Janson C, et al. End-of-life care in oxygendependent COPD and cancer: a national population-based study. Eur Respir J. 2015;46(4):1190-1193.

29. Ahmadi Z, Wysham NG, Lundström S, Janson C, Currow DC, Ekström M. End-of-life care in oxygen-dependent ILD compared with lung cancer: a national population-based study. Thorax. 2016;71(6):510-516.

30. Ekström MP, Bornefalk-Hermansson A, Abernethy AP, Currow DC. Safety of benzodiazepines and opioids in very severe respiratory disease: national prospective study. BMJ. 2014;348:g445. 


\section{Supplementary materials}

1. Is there a physician who is responsible for the oxygen service?

$\square$ Yes

$\square \quad$ No

2. Does a physician set the medical diagnosis of the patient before prescribing long-term oxygen therapy (LTOT)?

$\square$ Yes

$\square \quad$ No

3. Do you consistently register the health intervention code AG062 to a physician's appointment or inpatient occasion when starting LTOT?

$\square$ Always

口 Sometimes

- Rarely or Never

$\square \quad$ Have no information about this, don't know what it's about

4. How many full-time employments, defined as $\mathbf{4 0}$ hours/week, are allocated to oxygen personnel (registered nurses, assistant nurses, or physiotherapists)?

We realize that the question is difficult to answer since people have mixed duties, but we are grateful if you attempt to answer: ㄴ (number)

5. How many days a week are there oxygen personnel at the outpatient clinic/ward that works with oxygen patients?

$\square \quad$ (number)

6. Under which organization is the oxygen service provided?

$\square \quad$ Self-standing unit

$\square \quad$ Within a lung clinic

$\square \quad$ Within an allergy clinic

$\square$ Within a medicine clinic

$\square \quad$ Other service

7. How are personnel organized (registered nurses, assistant nurses, physiotherapists, technician), ie, do they work entirely with oxygen or with other services as well?

$\square$ Entirely with oxygen

口 Shared with CPAP or home-ventilation

口 Shared with allergy clinic

$\square \quad$ Shared with lung clinic

口 Other service

8. Highlight the oxygen courses that some of the personnel have attended.

$\square \quad$ Oxygen course arranged by Swedevox in association with Karolinska Institute, Stockholm

- AGA gas company

- AIOLOS Medical

$\square \quad$ Philips Respironics

- Other course

9. How long has the most experienced oxygen nurse worked with oxygen patients?

$\square \quad$ Less than one year
$\square \quad$ Less than five years
$\square \quad$ More than five years

10. Are you doing home visits to oxygen patients?

- Yes, both to them with LTOT and to them with palliative oxygen therapy

Yes, to those with LTOT

$\square \quad$ Only in selected patients

a No

11. Are you routinely undertaking a withdrawal attempt within three months?

$\square \quad$ Yes, we do that routinely

- Yes, we do that routinely to those who started LTOT during an exacerbation

- Sometimes

$\square \quad$ No

Figure SI (Continued) 
12. Who provides the oxygen equipment and information to the patient in the home?
$\square$ Oxygen nurse
- Medical technology personnel
․ Technician
Physiotherapists
Assistant nurse
- Other personnel

13. Are you using checklists as help at the initiation of LTOT?
$\square$ Yes
$\square \quad$ No

14. Are you keeping a separate list of the patients prescribed LTOT in addition to the Swedevox registration?
$\square$ Yes
$\square \quad$ No

15. Does the patient sign a non-smoking agreement before starting LTOT?
$\square$ Yes
No

16. Do you assess smoking after start of LTOT (COHb/urine)?
$\square$ Yes routinely
$\square \quad$ Yes, but only when suspicions about smoking
$\square \quad$ No

17. Are you performing a cognitive assessment, for example MMT (Mini Mental Test), on patients before LTOT start-up?
$\square$ Yes
$\square \quad$ No

18. Do you prescribe oxygen to children?
- Yes
$\square \quad$ No

19. Is there another service that prescribes palliative oxygen in your area? For example a palliative team?
$\square$ Yes
$\square \quad$ No

20. A) In palliative oxygen treatment at home, do you evaluate if patients experience relief within the first week?
$\square$ Usually
$\square \quad$ Sometimes
a Never
$\square$ Yes
$\square \quad$ No
- Sometimes

B) Only answers from you who evaluate palliative patients:

Do you withdraw the palliative oxygen therapy when patients do not experience relief?

21. Do you have time dedicated for registration in Swedewox?
$\square$ Yes
$\square \quad$ No

22. When after LTOT start-up is the patient registered in Swedewox?
Within 1-2 days
$\square \quad$ Within a week
$\square \quad$ Within a month
- Longer

23. Where do you normally do the evaluation when prescribing LTOT?
- Inpatient on the ward
- Outpatient clinic
$\square \quad$ The patient's home
$\square \quad$ Other

24. Do you perform the evaluation in hospital for patients with $\mathrm{CO}_{2}$ retention? $\left(\mathrm{PaCO}_{2}>6,5 \mathrm{kPa}\right)$
$\square$ Yes
$\square$ No

Figure SI (Continued) 
25. Do patients routinely perform a walk test with the prescribed oxygen dose before LTOT is prescribed at your clinic?

$\square \quad$ Yes always, patients walk for 6 minutes.

$\square \quad$ Yes, patients walk 500 meters.

$\square$ Sometimes

$\square \quad$ No

$\square$ Comments:

26. Do you get feedback on the data in the Swedevox registry at your unit, for example annually?

$\square$ Yes

$\square \quad$ No

Figure SI English translation of the web-based questionnaire from 2014.

Note: Intervention code AG062: this is a health code that refers to start of oxygen treatment.

Abbreviations: LTOT, long-term oxygen therapy; $\mathrm{PaCO}_{2}$, partial pressure of arterial carbon dioxide.

Table SI Variables in Swedevox registry

\begin{tabular}{|c|c|}
\hline Variable & Definition \\
\hline Birth date & Birth date from the Swedish Population Register \\
\hline Sex & Sex from the Swedish Population Register \\
\hline Primary and secondary causes of LTOT & Main and contributing physician-diagnosed cause(s) of starting LTOT \\
\hline Follow-up, years & Follow-up after starting LTOT \\
\hline Stop date and stop cause & Date and reason for discontinuing LTOT \\
\hline $\mathrm{PaO}_{2}$ air, kPa & Arterial blood gas tension of oxygen on air \\
\hline $\mathrm{PCO}_{2}$ air, $\mathrm{kPa}$ & Arterial blood gas tension of carbon dioxide on air \\
\hline $\mathrm{PaO}_{2}$ oxygen, $\mathrm{kPa}$ & Arterial blood gas tension of oxygen on oxygen \\
\hline $\mathrm{PaCO}_{2}$ oxygen, $\mathrm{kPa}$ & Arterial blood gas tension of carbon dioxide on oxygen \\
\hline $\mathrm{FEV}_{1}, \mathrm{~L}$ & Forced expiratory volume in I second \\
\hline $\mathrm{FEV}_{1}, \%$ of predicted & Forced expiratory volume in I second as percentage of predicted value \\
\hline VC, L & Vital capacity (the highest value of the slow and forced vital capacity) \\
\hline WHO status, n (\%) & World Health Organization Performance Status \\
\hline Height (cm) and weight (kg) & Height and weight \\
\hline Never smoker, \% & Smoking status \\
\hline Past smoker, \% & Smoking status \\
\hline Current smoker, \% & Smoking status \\
\hline Maintenance treatment with oral corticosteroids, \% & Long-term treatment with corticosteroids \\
\hline Oxygen dose, L/minute & Prescribed oxygen dose \\
\hline Oxygen duration, hour/24 hours & Prescribed oxygen duration \\
\hline
\end{tabular}

Abbreviations: $\mathrm{FEV}_{1}$, forced expiratory volume in I second; LTOT, long-term oxygen therapy; $\mathrm{PaO}_{2}$ (air), arterial blood gas tension of oxygen on air; SD, standard deviation; $\mathrm{PaO}_{2}$ (oxygen), arterial blood gas tension of oxygen on oxygen; $\mathrm{PaCO}_{2}$, partial pressure of arterial carbon dioxide; VC, vital capacity; WHO, World Health Organization.

\section{Publish your work in this journal}

The International Journal of COPD is an international, peer-reviewed journal of therapeutics and pharmacology focusing on concise rapid reporting of clinical studies and reviews in COPD. Special focus is given to the pathophysiological processes underlying the disease, intervention programs, patient focused education, and self management protocols

\section{Dovepress}

This journal is indexed on PubMed Central, MedLine and CAS. The manuscript management system is completely online and includes a very quick and fair peer-review system, which is all easy to use. Visit http://www.dovepress.com/testimonials.php to read real quotes from published authors.

Submit your manuscript here: http://www.dovepress.com/international-journal-of-chronic-obstructive-pulmonary-disease-journal 